RUNNING HEAD: Public and Private Revisited

Public and Private Revisited: Storied Reflections from a Food Allergy Parent

Jennifer J. Bute

Associate Professor

Department of Communication Studies

Indiana University-Purdue University Indianapolis

This is the author's manuscript of the work published in final form as:

Bute, J. J. (2020). Public and Private Revisited: Storied Reflections from a Food Allergy Parent. Health Communication. https://www.tandfonline.com/doi/full/10.1080/10410236.2020.1731779 


\section{Public and Private Revisited: Storied Reflections from a Food Allergy Parent}

The trauma, the confusion, the anxiety...it comes back to me in flashes, in bits and pieces. Sometimes I can tell a coherent story, but when I recall particular events, certain turning points, I remember small parts of a larger whole. I think it's self-protection, trying not to secondguess my decisions, our decisions, the advice of doctors. Trying never to ask "what if?"

"I don't care if you've been told it's something you're eating, it's not." This is what the dermatologist told me when Jack was a few months old, covered head to toe with eczema. His skin red and flaky. Our pediatrician had suggested that I try cutting dairy from my diet because the dairy in my breast milk might be the culprit in causing Jack's eczema. But the dermatologist in the small town where we lived at the time, the dermatologist I had begged to see Jack, crying on the phone to the receptionist because there was a months-long waiting list, she thought otherwise, and told me not to change my diet.

***

"Well, it looks like Jack has some pretty significant food allergies. I got the results of the bloodwork, and he tested positive to every food in the panel." This is what our pediatrician told me after we took my then 3-year-old son in for allergy testing after he had a reaction to a peanut he found on the floor at my mother-in-law's house.

"Give him some Benadryl and keep an eye on him." This is what the on-call doctor told me. I called about 5:30 p.m., after hours, as soon as I found out about Jack's reaction. Jack was in the car with my husband on his way home from his grandma's. I had no idea what state he'd be in when he got home. 
So much of my experience as a food allergy parent has involved retrospective sensemaking (Sharf \& Vandeford, 2003), as I think back over past events, educate myself and my family, and talk with other food allergy parents, bearing witness to their stories and trying to reconcile them with my own. I know now that our initial interactions with doctors, both when Jack was an infant and after his first allergic reaction, were clouded by bad advice and inaccurate information. Having shared my story with other food allergy parents in support group meetings and while conducting in-depth interviews, I learned that Jack's eczema was most likely foodrelated, a signal of the atopic march (American Academy of Allergy, Asthma, \& Immunology, 2020) wherein eczema is often the first sign of allergic disease. Maybe I should have changed my diet to save Jack the misery of the itchy skin he suffered for the first several years of his life. Maybe he wouldn't have food allergies now if we had gotten different advice, driven to a larger city to see an allergist.

I know now that Jack certainly was not allergic to every food on the panel when he was tested for the first time. In fact, many diagnostic tests for food allergies, including the bloodwork ordered by our pediatrician, have a 50\% false positive rate (Choosing Wisely, 2014). 50\% percent! If I had listened to our pediatrician, we would have eliminated peanuts, tree nuts, dairy, soy, wheat, egg, and corn from Jack's diet. His diet would have been severely and unnecessarily limited. I have since learned that experts urge physicians to avoid indiscriminate testing for food allergies because the current diagnostic tools are so inaccurate (Choosing Wisely, 2014).

I know now that Jack's first anaphylactic reaction was undertreated. He received no medication or medical attention of any sort when his symptoms began (none!), and the on-call pediatrician should not have told me to administer Benadryl. Epinephrine is the only medication 
that can halt anaphylaxis (American Academy of Allergy, Asthma, \& Immunology, 2020). Benadryl does not stop anaphylaxis. My mother-in-law should have called an ambulance, or my husband Brandon should have taken Jack to the hospital, or we should have sought medical attention the moment Jack was home. We were lucky. So, so lucky.

The turning point in our story, though, was Jack's second allergic reaction. Before Jack started school, I stayed home with him every Wednesday. On this particular day, we decided to bake a cake together. Jack had tried vanilla cake at preschool and wanted to bake one at home. We used a cake mix and a can of frosting and decided to wait to try the cake until after dinner. Once Brandon was home from work, we sat down to dinner, and Jack ate quickly so that he could try the cake. "My mouth hurts," he said, after taking a single bite. Brandon and I looked at each other. Shocked. Confused. Panicked. We rushed to get him water, as hives inflamed his skin and he started vomiting profusely. We gave him Benadryl (stupid-- Benadryl does not stop anaphylaxis.). We didn't know this. We didn't know that the brand of cake mix we had used did not label for cross-contact, which meant that a miniscule amount of an allergen might have triggered the reaction. We didn't know that such labels (e.g., may contain...processed in the same facility...made on shared equipment) are not required by law and are not regulated by the FDA (Marchistto et. al, 2017). We knew nothing. After a few minutes, Jack was fine. We were lucky. So, so lucky.

I had to teach myself everything — about allergy testing, about food labels, about epinephrine. I had to meet other food allergy parents - I needed stories from real people to understand my own experience, our family's experience. I wanted to research the stories of other families. Were there stories like mine? Was I the only one who had made so many mistakes? So many potentially fatal mistakes? 
While I have previously dwelled on the intersection of the personal and the professional (Bute, 2011), it feels like there's more at stake this time. Why are food allergies mocked over and over in TV and movies (Abo, Slater, \& Jain, 2017), even in media designed for children (Feng \& Kim, 2019)? Why is there currently just a single FDA-approved treatment that is only for one allergen (peanut), a treatment that is not curative? Why do people look at me in disbelief when I try to explain food allergies? Why does my mother-in-law insist on adding the pecans to the sweet potato casserole even though a microscopic amount would be like a tiny bomb of poison exploding in Jack's body (over time we have verified his allergies to peanuts and tree nuts)?

Like so many others (Harter, Ellingson, Yamasaki, Hook, \& Walker, 2020), my story called me to public advocacy. I couldn't help but wonder what I could do in a situation that made me feel so oblivious and so entirely powerless. How could I change the landscape of food allergy life? If I, a highly-educated woman who had the means to spend $\$ 100$ on cardboard gingerbread houses so Jack's second-grade class could make non-food crafts, who had access to peer-reviewed research on emerging therapies, who could afford multiple Epi-Pens even as their price skyrocketed, if I had struggled to learn how to manage this disease, what about other parents and children who didn't have access to the same financial and informational resources?

I spent three years serving on the Outcomes Research Advisory Board and one year serving on the Community Engagement Council for Food Allergy Research \& Education, the largest private funder of food allergy research in the U.S. While this was a wonderful and fulfilling experience that allowed me to shape the future of food allergy research (Bute, Broome, Marcus, Mikulcik, \& Vickery, 2018), it's also been fraught with tension, as I was faced with information and experiences that conflicted with my own understandings, encountered 
organizational leadership changes that have challenged my ability to participate, and wrestled with complex scientific information, some of which linked maternal and child health in ways that appeared to blame women (mothers) for the development of food allergies.

I was also called to interview other food allergy parents. To explore a context virtually untouched by health communications scholars, even though the management of food allergy is almost entirely communicative in nature, to find out how other parents legitimate and manage their child's allergies in everyday talk. Yet this work, like my advocacy work, is not without peril. Every story of witnessing anaphylaxis makes my heart race. Every retelling of a doctor's bad judgement makes me angry. Every parent whose food allergy management differs from my own makes me anxious.

For scholars of health communication, we must recognize how we are confronted daily with human suffering, suffering that may or may not mirror our own, and then decide how to make sense of these narratives while attending to our own vulnerabilities. Is a peer-reviewed journal publication, the gold standard of promotion and tenure, a worthwhile outcome? To what extent must we become public advocates, even for issues with which we have no intimate experience, and especially for those with which we do? And how do we protect ourselves while consciously reflecting on our own positionality as we treat all stories with tenderness and care? 


\section{References}

Abo, M. M., Slater, M. D., \& Jain, P. (2017). Using health conditions for laughs and health policy support: The case of food allergies. Health Communication, 32, 803-811.

American Academy of Allergy, Asthma, \& Immunology. (2020, February 7). Anaphylaxis. https://www.aaaai.org/conditions-and-treatments/allergies/anaphylaxis

American Academy of Allergy, Asthma, \& Immunology. (2020, February 7). Atopic march definition. https://www.aaaai.org/conditions-and-treatments/conditions-dictionary/atopic$\underline{\operatorname{march}}$

Bute, J. J., Broome, S. B., Marcus, J. N., Mikulcik, S., \& Vickery, B. (2018). Development of a patient-centric food allergy research program: A model for action. Allergy, 73, 15511553.

Choosing Wisely (2014, March 3). Don't perform food IgE testing without a history consistent with potential IgE-mediated food allergy. http://www.choosingwisely.org/clinicianlists/american-academy-allergy-asthma-immunology-food-ige-testing/

Harter, L. M., Ellingson, L. L., Yamasaki, J., Hook, C., \& Walker, T. (2020). Defining Moments... Telling Stories to Foster Well-being, Humanize Healthcare, and Advocate for Change. Health Communication, 35, 262-267.

Marchisotto, M. J., Harada, L., Kamdar, O., Smith, B. M., Waserman, S., Sicherer, S., ... \& Gupta, R. S. (2017). Food allergen labeling and purchasing habits in the United States and Canada. The Journal of Allergy and Clinical Immunology: In Practice, 5, 345-351.

Sharf, B. F., \& Vandeford, M. L. (2003). Illness narratives and the social construction of health. In T. L. Thompson, A. Dorsey, K. I. Miller \& R. Parrott (Eds.), Handbook of health communication. (pp. 9-34) Mahwah, NJ: Erlbaum. 